\title{
ADDITIVE MANUFACTURING / 3D PRINTING TECHNOLOGY: A REVIEW
}

\author{
R. M. Mahamood1,2*, S. A. Akinlabi2, M. Shatalov, E. V. \\ Murashkin ${ }^{4}$ E. T. Akinlabi² \\ ${ }^{1}$ Department of Mechanical Engineering, University of Ilorin, Nigeria \\ ${ }^{2}$ Department of Mechanical Engineering Science, University of Johannesburg, Auckland Park Kingsway \\ Campus, Johannesburg, 2006, South Africa \\ ${ }^{3}$ Thwane University of Technology, Pretoria, South Africa \\ ${ }^{4}$ Ishlinsky Institute of Problems in Mechanics, Russian Academy of Science \\ *Corresponding Author's Email address: mahamoodmr2009@gmail.com
}

\begin{abstract}
Additive manufacturing (AM) also known as three dimensional (3D) printing is an important advanced manufacturing method that will change the way machines and consumer good are made. This technology is where the human creativity meets technology. AM allows product to be fabricated from the $3 D$ computer aided design $(C A D)$ model of the part, no matter the complexity, through addition of materials one layer at a time until the building is completed. In this article, the seven classes of AM, the advantages in the additively manufactured products as compared to the existing counterparts are highlighted and some of the research efforts in this technology are presented. Some of the problems and the future research need in this field are also presented.
\end{abstract}

KEYWORDS: AM, Laser metal deposition, Selective laser sintering, Sheet lamination, Stereo lithography.

\section{INTRODUCTION}

Additive manufacturing (AM) is an advanced method of manufacturing that builds up components into complex shape by adding materials layer after layer. This is unlike the traditional manufacturing process that involves a number of manufacturing processes including material removal to achieve the complex shape desired. The first AM technology appeared in the 1987 when stereolithography was invented by Hull of 3D systems [1]. The next challenge for the researchers was the development of materials for the new technology. This resulted in the development of acrylate resins by $3 \mathrm{D}$ systems in conjunction with Ciba-Geigy in 1988 [2].

Similar technologies were also commercialized by NTT Data CMET in Japan and Sony/D-MEC in 1988 and 1989 respectively. The technologies were called solid object ultraviolet plotter (SOUP) and solid creation systems (SCS) by NTT and Sony respectively. In 1988, the first epoxy resin used on stereolithography machine was developed by Asahi Denka Kogyo [2]. Also, in 1989, Japan synthetic Rubber and DSM Desotech produce resin for the stereolithography equipment [2]. Through research and developments, a number of resins have been developed for the system. Another important AM technology, namely fused deposition modelling
(FDM), was commercialized by Stratasys in 1991. Solid ground curing and laminated object manufacturing were commercialized by cubital and Helisys respectively. Selective laser sintering and solid form stereolithography system were commercialized by DTM and Teijin Seiki respectively in 1989 and 1992 [2], [3].

In 1998, Optomech commercialized its laser engineered net shaping (LENS) which was based on the technology that was developed at Sandia national laboratory in the mid-nineties. Many additional AM technologies have been introduced since then and before the end of last decade, over thirty AM technologies have already appeared [4].

A number of modified AM technologies have been developed and, with patents' expirations, the prices of AM equipment have witnessed a downward review making them more and more affordable. The large number of AM technologies was beginning to confuse the user which resulted in the classification of AM technologies into seven classes [5].

In this paper, these seven classes of AM technologies are presented. The advantages in the AM products over those manufactured through existing manufacturing processes are highlighted. Some of the research works in AM technologies are presented. The current problems and the future research needs in this field are also presented. 


\section{CLASSIFICATION OF ADDITIVE MANUFACTURING TECHNOLOGIES}

Additive manufacturing technologies are grouped into seven main classes namely: binder jetting, direct energy deposition, material extrusion, powder bed fusion, sheet lamination, vat photo-polymerisation. Each of these classes of AM technologies is briefly explained in the following subsections.

\subsection{Binder Jetting}

Binder jetting is a class of additive manufacturing where the technologies in this group create three dimensional (3D) objects by placing a binding agent on powder stock material in order to join the powder particles together. The powder materials used in this class of additive manufacturing include metals, polymers and ceramic materials [6]-[11]. The AM technologies that belong to this class include 3D printing, ink-jetting, s-print, and M. print. The schematic diagram of this class of additive manufacturing processes is shown in figure 1 .

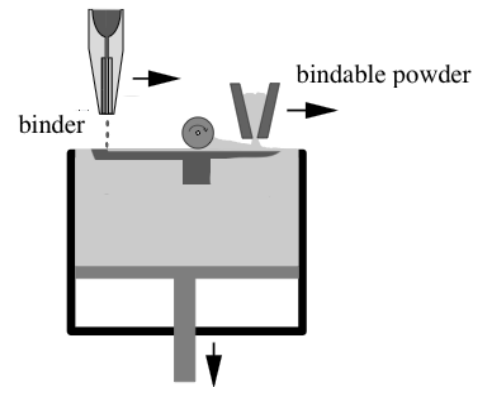

Fig. 1. Schematic diagram of Binder Jetting

\subsection{Directed Energy Deposition}

Directed energy deposition is a class of AM technologies that produces 3D object by using thermal energy to melt or fuse materials together following the path dictated by the $3 \mathrm{D}$ path. The thermal energy first creates a melt pool on the surface of the substrate material, and then the deposited material is introduced into the melt pool. The materials used in this class of AM technologies include powder and wire of metals, and ceramic materials [12] - [19]. The AM technologies that belong to this class of AM technology include: direct metal deposition, laser metal deposition process, electron beam direct melting and laser consolidation. The schematic diagram of the process is shown in figure 2 .

\subsection{Material Extrusion}

Fused deposition modelling is an additive manufacturing that belong to this class of AM technology. It creates $3 \mathrm{D}$ object by ejecting material through a nozzle and depositing it layer after layer to produce the solid object desired from the 3D model of the part. The materials used in this class include polymers and metals [20] - [23]. The schematic diagram of material extrusion class of AM technologies is shown in figure 3 .

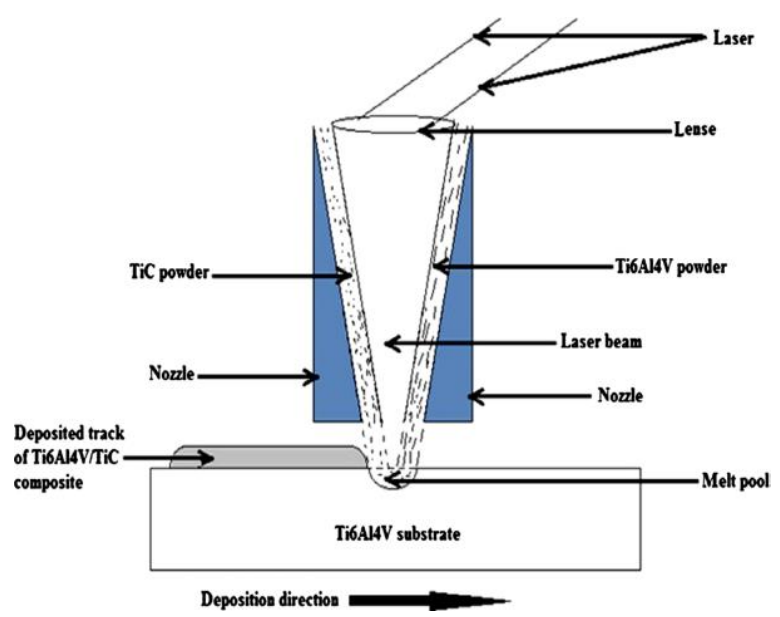

Fig. 2. Schematic Diagram of Directed Energy Deposition Process [19]

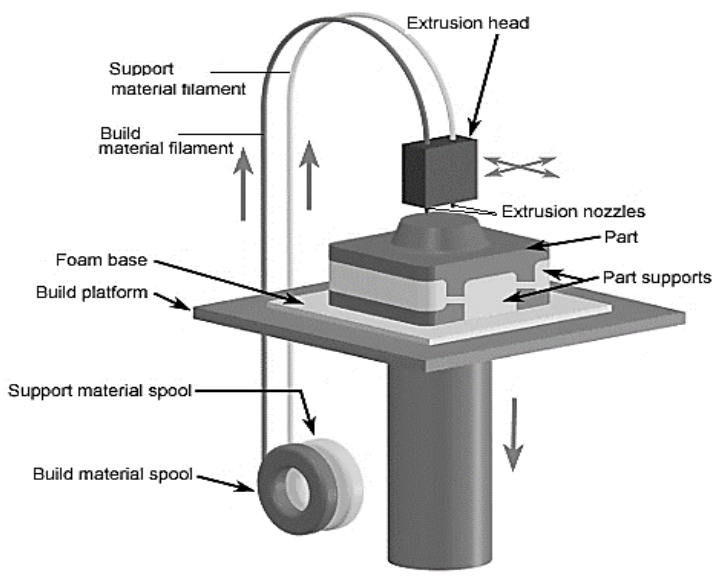

Fig. 3. Schematic Diagram of Material extrusion

\subsection{Material Jetting}

Material jetting produces 3D object by depositing small droplets of build material that is then cured by exposing it to light [24] - [28]. This process is repeated layer after layer until the part building is completed. The materials used in this class of Am technologies include photopolymer and wax. A photopolymer is a type of polymer that changes its physical properties when exposed to light. The AM technologies in this class include polyject, ink-jetting and thermojet. The schematic diagram of material jetting is shown in figure 4 .

\subsection{Powder Bed Fusion}

This class of AM technology produces 3D objects by preplacing powder on the build platform called the 
powder bed, and then the thermal energy is used to fuse or melt the powder together along the path of the thermal energy. The materials used in this class of AM technology are metal, ceramic and polymer [29].

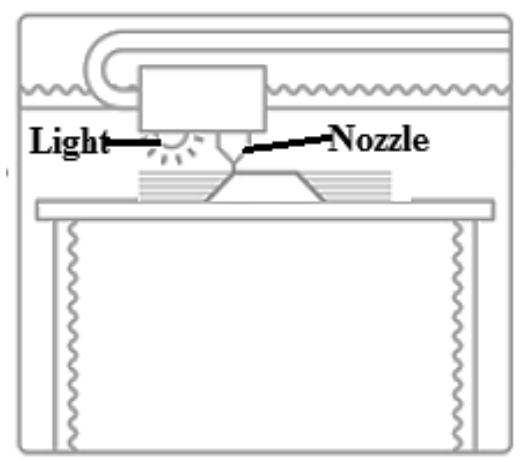

Fig. 4. Schematic diagram of Material jetting

The AM technologies that belong to this class of AM technologies include: direct metal laser sintering, selective laser melting selective laser sintering, electron beam melting [30]. The schematic diagram of powder bed fusion is shown in Figure 5.

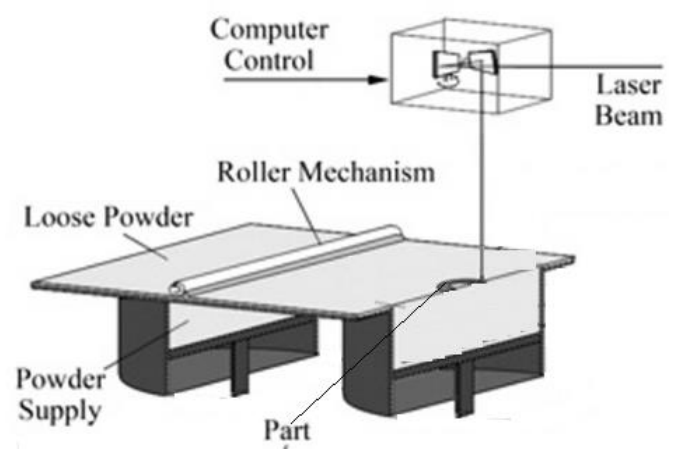

Fig. 5. Schematic diagram of powder bed fusion

\subsection{Sheet Lamination}

This class of AM technologies produces 3D objects by binding material together in layers and trimming the sheets as required, to produce the complex shape. Materials used in this class of AM technology include metals, ceramic, wood and paper [31] - [40]. The AM technologies that belong to this class of AM technologies include laminated object manufacture and ultrasonic consolidation. The schematic diagram of the sheet lamination is shown in Figure 6.

\subsection{Vat Photopolymerisation}

Vat photopolymerization is a class of AM technologies that achieve building of 3D parts by selectively curing layers of photopolymer materials based on the path dictated by the $3 \mathrm{D}$ model of the path. The AM technologies in this class of AM technologies include stereolithography and digital light processing [41], [42]. The schematic diagram of vat photopolymerisation is shown in Figure 7.

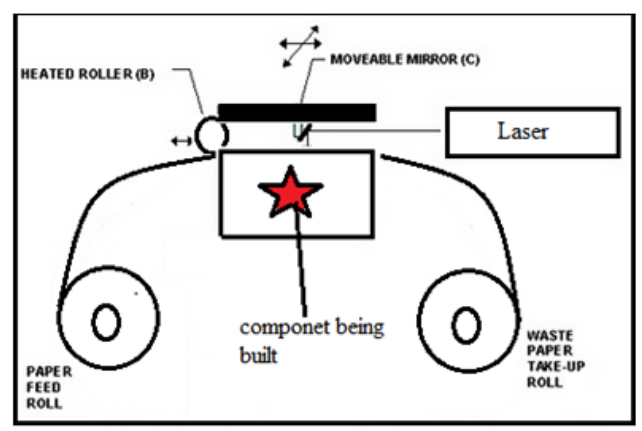

Fig. 6. Schematic diagram of sheet lamination

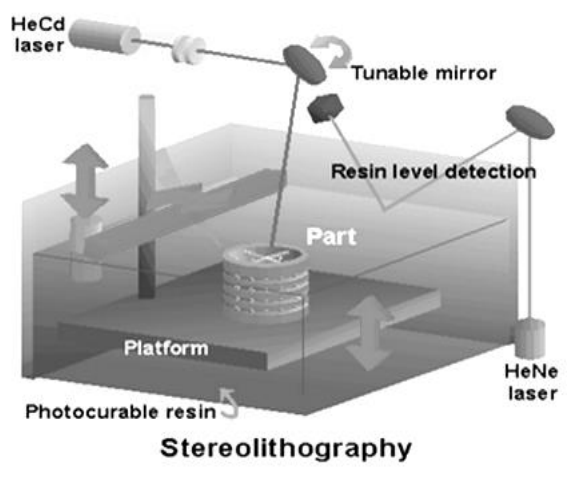

Fig. 7. Schematic diagram of vat photopolymerisation

\section{3D PRINTING USED IN PRODUCTS AND EQUIPMENT MANUFACTURING}

A typical car is made up of over 30,000 different parts that are made using different manufacturing methods. This occurs as a result of available traditional manufacturing processes which necessitated the breaking of a complex part into smaller parts resulting in a large number of parts. With additive manufacturing technology, a complex part can be produced as a single part. Other benefits of employing the AM technology for production of car parts include the reduction in weight due to elimination of additional materials used for joining and assembling of parts. Reduction in material loss is another important benefit.

The actual materials needed for the part are used, since the part is built up by adding material layer after layer. It also makes it possible to create customized 3D printed car parts. It offers the opportunity to easily replace spare parts and saving time in part production. The unibody of a car is the spine of any car. It is the part of the car that absorbs pushes and bumps that the car may experience.

The complex manufacturing methods that were used in producing the unibody makes it difficult to repair, hence additive manufacturing is an ideal manufacturing process for the unibody because of its ability to replace damaged parts. AM processes are 
also used to produce Interior parts such as dashboard, gauges, dials, switches, air conditioner vents, door handles, floor mats, and seat belts which can fully be customized. Porsche is using additive manufacturing process to manufacture its rare vehicle's spare parts. Because these vehicles are customized and the original spare parts are not being produced any longer, they are now produced by additive manufacturing technology. Porsche finds the use of additive manufacturing process more economical. Rolls-Royce is also taking advantage of additive manufacturing technologies for the production of their customized luxury cars that will allow drivers to completely personalize their cars. The Rolls-Royce 103EX has design that will allow for the inside and outside to be customized by the driver.

The mass customization advantage that is offered by additive manufacturing technologies [43] provides the enabler technology for the automobile industries to satisfy their wide range of customers' need. BMW creates customized service for BMW MINI users where they can indicate the options they will like to have implemented or specific parts of the BMW MINI. A host of other automobile manufacturers are also taking advantage of additive manufacturing technologies for the production of their car parts.

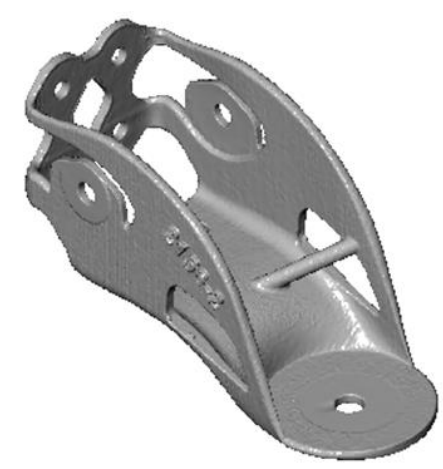

Fig. 8. Titanium based-alloy satellite bracket made by Additive Manufacturing [44]

The light weight offered by the additively manufactured part, a typical part as shown in figure 8, contributes immensely to the low fuel consumption in any moving or flying parts, hence reducing the carbon footprint of these industries. Aerospace industries are greatly benefiting from additive manufacturing technologies because parts can now be produced with improved buy-to-fly ratio. Additive manufacturing technologies are now being used to produce aerospace engine, turbine parts and cabin interior components. AM technology can be used to produce cost effective functional parts with complex shapes that comply with aerodynamic properties. Leading aerospace companies like Boeing has integrated additive manufacturing into their production run. The aerospace industries are able to achieve up to $60 \%$ weight reduction in their parts produced using additive manufacturing technologies. The medical and petrochemical industries are also having their fair share of additive manufacturing technology. The highly customized medical implants are produced at no additional cost using additive manufacturing technologies making the technology the number one choice of manufacturing in the industry.

\section{RESEARCH ADVANCEMENT IN ADDITIVE MANUFACTURING TECHNOLOGY}

Currently, there are a number of research works in additive manufacturing technologies. Most of these research works are carried out for better understanding additive manufacturing processes while orders are aimed at solving problems that are preventing a number of AM technologies to pass certification processes. Some of these research efforts are presented in this section.

The challenges of most AM parts include porosity and defect. Zanini et al. [45] used Micro Xray computed tomography to study dimensional evaluations, porosity analysis and surface topography measurements of AM parts. The authors carried out experimental investigations on different selective laser melted of Ti6Al4V. The results revealed that the thickness analysis was found to be sensitive to the surface quality. The search angle optimization was also found to improve the surface topography and the thickness analysis samples. The investigation also revealed that for larger pores it was possible to evaluate internal porosity with diameter below $5 \mu \mathrm{m}$ and for volume below $5 \%$.

Gao et al. [46] presented the barriers, evolution and future research trends in additive manufacturing. The research revealed that additive manufacturing has the potential to re-imagine current research and provide new avenues for research exploration.

Yadollahi and Shamsaei [47] also presented the various mechanical characteristics of metallic parts produced using additive manufacturing and the challenges and opportunities in fabricating materials using AM technology with increased fatigue resistance. The study suggested that standards for mechanical testing methods, specimen design procedures, and post manufacturing treatments need to be revised for AM parts.

Stavropoulos et al. [48] presented a roadmap for the industrial application of AM by addressing the challenges that hindered it with a Hybrid of solution framework that is tailored to the industrial need.

Ford and Despeisse [49] studied the sustainability of additive manufacturing processes and found that additive manufacturing has benefits in product and material life cycles due to product and process redesign. The authors highlighted the advantages and challenges of additive manufacturing on sustainability.

Krujatz et al. [50] conducted a review on the 
historical background, their current implementations and some of the major challenges of AM in biotechnology/bioprocess engineering. The capability of additive manufacturing technologies in handling more than one material at the same time gives rise to the opportunity of manufacturing components that are made of composite and functionally graded materials (FGM). This huge benefit is achieved in a single manufacturing run. A number of research works on composites and functionally graded materials using $\mathrm{AM}$ technologies are reported in the literature. Some of the works include those of: Obiolodan and Strucker, [51]. These authors studied the fabrication of composites of 10 and $5 \mathrm{w} \% \mathrm{TiC} / \mathrm{Ti} 6 \mathrm{Al} 4 \mathrm{~V}$ using laser metal deposition process.

Popoola et al. [52] studied alloys of TiC/Ti6Al4V composite at various TiC compositions. Wang et al. [53] also investigated additive manufactured TiC/Ti6Al4V composite at different TiC compositions. Ochonogor et al. [54] studied the effect of the $\mathrm{TiC}$ ratio on the wear resistance performance of $\mathrm{Ti} / \mathrm{TiC}$ composite, using laser metal deposition. Some authors have also studied functionally graded Ti6Al4V/TiC composite [51, 55, 56]. The importance of producing functionally graded parts directly from the 3-D CAD model in one single step has been the driving force for the research interest in FGM, by using laser metal deposition (LMD) process.

The earlier works tried to establish the feasibility of making FGM through the LMD process [57]. In a study conducted by Zang et al. [56], functionally graded $\mathrm{Ti} / \mathrm{TiC}$ was deposited on a Ti6Al4V substrate. They first established the processing parameters for various volume fractions of $\mathrm{Ti} / \mathrm{TiC}$ composite in their preliminary works. They used the results from their preliminary work to successfully deposit a thin wall of functionally graded material - by adjusting the processing parameters during the deposition process. They showed that the wear-resistance performance of the Ti6Al4V substrate was improved with the addition of TiC. They also showed that FGM can be produced with LMD without a discrete interface. In their preliminary studies, the method used to obtain the optimal process parameters for the various premix of $\mathrm{Ti}$ and $\mathrm{TiC}$ was not clear. Also, premixing the powder before deposition can result in having the powder with higher density to be deposited first, before the less dense powder. And this could affect the results (density of $\mathrm{Ti}$ is $4.5 \mathrm{~g} / \mathrm{cm}^{3}$ and that of $\mathrm{TiC}$ is 4.93 $\left.\mathrm{g} / \mathrm{cm}^{3}\right)$. This could be one of the reasons why they observed cracking in the deposit at $40 \% \mathrm{TiC}$.

In another study performed by Wang et al. [55], a functionally graded material of $\mathrm{Ti} 6 \mathrm{Al} 4 \mathrm{~V} / \mathrm{TiC}$ was deposited. They used Ti6Al4V wire and TiC powder; and the two materials were fed simultaneously. They achieved the compositional grading by keeping the wire feed rate of Ti6Al4V constant; while they varied the $\mathrm{TiC}$ powder feed rate. Also, other processing parameters were kept constant. They did not consider the effect of processing parameters on the resulting deposit properties. Liu and DuPont [58] successfully deposited functionally graded material of $\mathrm{Ti} / \mathrm{TiC}$ composite using LMD. They relied on the controller in LENS, which monitors the melt pool area and controls the laser power to achieve a constant melt pool area, for the deposition of their FGM. The melt pool area control in LENS is intended to control the dimensional accuracy in the deposited part. Shah [59] deposited functionally graded material of Inconel 718 Nickel alloy and Ti6Al4V using the laser-metal deposition process. The effect of the laser pulse parameters and the powder flow rate on residual stress was studied. The study found that the layer thickness plays an important role in the crack behaviour of the functionally graded material produced. The effect of the powder flow rate on the melt pool size was also studied; increasing the powder flow rate was found to increase the melt pool size. Lin et al. [60] used the laser-metal deposition process to produce functionally graded material of stainless steel-SS316L/super alloyRene88DT. They investigated the solidification behaviour and the microstructural evolution of the FGM. Epitaxial growth and columnar dendrites' microstructure were also observed. Insitu functionally graded material using the laser-metal deposition process was also studied in the literature. Qin et al. [61] produced in situ functionally graded $\mathrm{TiC}$ reinforced titanium matrix from $\mathrm{Ti}$ and $\mathrm{Cr}_{3} \mathrm{C}_{2}$ powder using laser metal deposition process. The functionally graded material was achieved by changing the powder flow rate of the $\mathrm{Ti}$ and the $\mathrm{Cr}_{3} \mathrm{C}_{2}$ powder. The microhardness and the wear-resistance properties were studied. The microhardness and the wear resistance were found to be greatly improved.

The problem with functionally graded material produced in situ is that the magnitude of the reinforcement achieved will largely depend on the reactions taking place during the deposition and cooling process. It would be very difficult to achieve a desired percentage ratio of the reinforcement and the matrix. Also, there is no doubt that different Ti6Al4V/TiC ratios would have different optimal process parameters; but these were not considered in the above studies. It has also been demonstrated that having powders placed in separate hoppers is an effective way of producing composite, with proper composition control, and without segregation due to difference in the densities of the powders [62]. Javaid and Haleem [63] presented research works on the application of additive manufacturing in orthopaedics. The study showed that research on additive manufacturing applications in the field of orthopaedics is on the increase, especially for patientspecific orthopedic applications, such as in lumbar discectomy, pelvic surgery and large scapular. It revealed that an orthopaedic surgeon can convert his or her need into a reality by using computer-aided design (CAD) model of the human part and then 
produce the needed part using the AM technology. Also, AM are used to produce orthopaedic implantable medical devices. Additive manufacturing technologies can be used to fabricate on-demand production of customized surgical instruments, 3D printed bone, and biologic implants that are used in orthopaedics restoration of function and original structure.

Allevi et al. [44] investigated stress Analysis on a titanium based-alloy space bracket, produced using Electron Beam Melting (EBM) using a NonDestructive Dimensional Measurement (triangulation system for reverse engineering). Araya-Calvo et al. [64] also studied mechanical behaviour of additively manufactured part of polyamide 6 (PA6) reinforced with carbon fiber. The influence of reinforcement pattern, reinforcement distribution, print orientation and percentage of fibre on mechanical properties was investigated. The study revealed that a maximized flexural response was achieved with 0.4893 Carbon Fibber volume ratio, concentric reinforcement and perpendicular to the applied force, producing a flexural modulus of $14.17 \mathrm{GPa}$ and a proportional limit of $231.1 \mathrm{MPa}$.

Reddy et al. [65] conducted a research to identify the areas that are hindering the adaptability of Metal Additive Manufacturing to the industries. The constrains were identified as part identification, static strength analysis, design intent, materials properties, and process parameters. An aero structural part, Flap Lever, was developed as 3D model by using CATIA software, was selected for this study. Static strength checks were performed on the specimen, followed by optimization with respect to the design intent of weight optimization and savings on build to fly ratio, fuel costs, time to market, etc. The Flap lever component was successfully optimized based on the design intent. The result showed that the optimized part has a reduced weight of about $2 / 3 \mathrm{rd}$ of its initial volume and better margin of safety. The literature is very rich in terms of research on additive/3D printing that can further be consulted [66]-[72].

\section{FUTURE RESEARCH DIRECTIONS}

The advantages offered by additive manufacturing technologies have made them an important future manufacturing process, and continuous research effort are constantly being invested to improve the technology and properly position it for the $4^{\text {th }}$ industrial revolution. AM technologies have lots of advantages that include their ability to fabricate very complex and smart structures with embedded components such as sensors, actuators or capillaries for temperature control and the short lead time offered by additive manufacturing. The ability to fabricate parts such as medical implants directly from 3D-data, has been obtained by using scanning devices as computerized tomography instruments, laser scanning devices or magnetic resonance imaging. Despite these exciting properties of AM technologies, there are still many challenges facing the use of AM technologies. These include the time consuming and costly postfabrication processes such as polishing. Also, the need for high level of part accuracy and proper part material certification is still a big issue. There is a need to expand the limited range of materials used in $\mathrm{AM}$ processes that requires the researchers to start thinking outside the box because with AM technologies our orientation should change completely from the traditional ways of doing things. AM technologies have helped to remove many limitations of the traditional ways of designing and product manufacturing. There is a serious need in the area of process control and in sensor systems development which will help to reduce process variability across different AM devices. Researchers should continue to explore the benefits of heterogeneous material property for better design performance in AM technologies. This may result in an overwhelming benefit that we have never imagined. Also, future research should be directed towards how complex multimaterial objects can be generated simply by specifying design performance during the design process using efficient simulation algorithms. There is a need for other methods to develop geometric computation for 3D models for additive manufacturing. Researchers should look up to nature for inspiration and ideas such as selfassembly, biologically and ecologically inspired printing approaches. More research effort is needed in AM-based repair/remanufacturing. This will help to further improve existing product life and material life cycle. The future of manufacturing relies on AM technologies and this technology needs to live up to the expectations placed on it through active research that will further improve and position AM technology at the fore front. Four dimensional (4D) printing is a value added technology that helps to create reconfigurable AM or 3D printed parts. 4D Printing technology is achieved by using programmable and advanced materials to produce a $3 \mathrm{D}$ printed component that is capable of changing its shape and configuration in predetermined conditions such as temperature and humidity in order to perform different functionality. In 4D printing, through computational folding, objects larger than the AM machine envelope can be printed as a single part and then change shape, shrink, fold and unfold, into their required secondary shape. This capability brings about the flexibility that is not available with the AM produced part. There is a need for further research works into smart material development to further expand the benefit of additive manufacturing technology/3D printing and 4D printing. With further research work on 4D printing, a number of applications will evolve and the current application of 4D printing (such as architecture, and biomedical) will expand. 


\section{CONCLUSION}

Additive manufacturing, also known as three dimensional (3D) manufacturing, was the main subject of this paper. Due to the flexibility offered by the additive manufacturing technologies, they are favoured in many industries, including automotive, aerospace and medical industries. The applications of $3 \mathrm{D}$ printing, especially in automotive and aerospace industries, are preferred to be used, due to the light weight of the components achieved. Light weight is important in moving and flying actions, because the lighter the moving parts are, the better the fuel efficiency.

Some of the research efforts made in this field, as well as several future research directions are emphasised, too. To enable the 3D printing to live up to its expectations in the next industrial revolution, there is a need for further research activities which are highlighted in this review.

\section{ACKNOWLEDGEMENTS}

This project was supported by SA/Russian grant.

\section{REFERENCES}

[1] Hull C. W., Apparatus for Production of Three-dimensional Objects by Stereolithography, US Patent 4575330, 1986.

[2] Wohlers T. and Gomet T., Wohlers Report 2014 History of Additive Manufacturing, August, 2019.

[3] Deckard C., Methods and Apparatus for Producing Parts by Selective Laser Sintering, US Patent 4863538, 1989.

[4] Banerjee S., Development of a Novel Toner for Electrophotography Based Additive Manufacturing Process, $\mathrm{PhD}$ thesis, De Montlbrt University, 2009.

[5] *** ASTM F2792-12a: Standard Terminology for Additive Manufacturing Technologies, DOI:10.1520/F2792-12A

[6] Dini F., Ghaffari S. A., Jafar J., Hamidreza R., Marjan S., A review of binder, printing and sintering condition, Metal Powder Report 2019, in press, corrected proof.

[7] Corson L. Cramer, Natalie R. Wieber, Trevor G. Aguirre, Richard A. Lowden, Amy M. Elliott., Shape retention and infiltration height in complex WC-Co parts made via binder jet of WC with subsequent Co melt infiltration, Additive Manufacturing, vol. 29, 2019, 100828

[8] Ayres T. J., Sama S. R., Joshi S. B., Manogharan G. P., Influence of resin infiltrants on mechanical and thermal performance in plaster binder jetting additive manufacturing, Additive Manufacturing, vol. 30, 2019, 100885.

[9] Coelho A.W.F., Thiré R. M.S., Araujo A.C., Manufacturing of gypsum-sisal fiber composites using binder jetting, Additive Manufacturing, vol. 30, 2019, 100789.

[10] Cramer C. L., Aguirre T. G., Wieber N. R., Lowden R. A., Trofimov A., Wang H., Yan J., Paranthaman M. P., Elliott A. M., Binder jet printed WC infiltrated with pre-made melt of WC and Co., International Journal of Refractory Metals and Hard Materials, 2019, 105137, In Press.

[11] Bai Y., Williams C. B., Binder jetting additive manufacturing with a particle-free metal ink as a binder precursor, Materials and Design, vol. 147, 2018, pp. 146-156

[12] Jinoop A.N., Paul C.P., Mishra S.K., Bindra K.S., Laser Additive Manufacturing using directed energy deposition of Inconel-718 wall structures with tailored characteristics, Vacuum, vol. 166, 2019, pp. 270-278

[13] Saboori A., Aversa A., Bosio F., Bassini E., Librera E., De Chirico M., Biamino S., Ugues D., Fino P., Lombardi M., An investigation on the effect of powder recycling on the microstructure and mechanical properties of AISI 316L produced by Directed Energy Deposition, Materials Science \& Engineering A, vol. 766, 2019, 138360, In Press.

[14] Farayibi P. K., Abioye T. E., Kennedy A., Clare A. T., Development of metal matrix composites by direct energy deposition of 'satellited' powders, Journal of Manufacturing Processes vol. 45, 2019, pp. 429-437.

[15] Ren Y. M., Lin X., Guo P. F., Yang H. O., Tan H., Chen J., Li J., Zhang Y. Y., Huang W.D., Low cycle fatigue properties of Ti-6Al-4V alloy fabricated by high-power laser directed energy deposition: Experimental and prediction, International Journal of Fatigue, vol. 127, 2019, pp. 58-73.

[16] Pityana S., Mahamood R.M. Akinlabi E.T., Shukla M., Effect of gas Flow Rate and powder flow rate on Properties of Laser Metal Deposited Ti6Al4V, International Multi-conference of Engineering and Computer Scienc, IMECS 2013, pp. 848-851.

[17] Mahamood R. M., Akinlabi E. T., Effect of Processing Parameters on Wear Resistance Property of Laser Material Deposited Titanium -Alloy Composite, Journal of Optoelectronics and Advanced Materials, vol. 17, 2015, pp. 1348 - 1360.

[18] Shukla M., Mahamood R. M., Akinlabi E. T. and Pityana S., Effect of Laser Power and Powder Flow Rate on Properties of Laser Metal Deposited Ti6Al4V, World Academy of Science and Technology, vol.6, 2012, pp. 44-48.

[19] Mahamood R. M., Akinlabi E. T., Shukla M., Pityana S., Scanning Velocity Influence on Microstructure, Microhardness and Wear Resistance Performance on Laser Deposited Ti6Al4V/TiC Composite. Materials and Design, vol.50, 2013, pp. 656-666.

[20] Braconnier D. J., Jensen R. E., Peterson A. M., Processing Parameter Correlations in Material Extrusion Additive Manufacturing, Additive Manufacturing, vol. 31, 2020, 100924.

[21] Gonzalez-Gutierrez J., Arbeiter F., Schlauf T., Kukla C., Holzer C., Tensile properties of sintered 17-4PH stainless steel fabricated by material extrusion additive manufacturing, Materials Letters, vol. 248, 2019, pp. 165-168.

[22] Serdeczny M. P., Comminal R., Pedersen D. B., Spangenberg J., Experimental validation of a numerical model for the strand shape in material extrusion, Additive Manufacturing, vol. 24, 2018, pp. 145-153.

[23] Comminal R., Serdeczny M. P., Pedersen D. B., Spangenberg J., Motion planning and numerical simulation of material deposition at corners in extrusion additive manufacturing, Additive Manufacturing, vol. 29, 2019, 100753, in press.

[24] Shen X., Naguib H. E., A robust ink deposition system for binder jetting and material jetting, Additive Manufacturing, vol. 29, 2019, 100820, in Press.

[25] Dilag J., Chen T., Li S., Bateman S. A., Design and direct additive manufacturing of three-dimensional surface microstructures using material jetting technologies, Additive Manufacturing, vol. 27, 2019; pp. 167-174.

[26] Sturm L. D., Albakri M. I., Tarazaga P. A., Williams C. B. In situ monitoring of material jetting additive manufacturing process via impedance based measurements, Additive Manufacturing, vol. 28, 2019, pp. 456-463.

[27] Salcedo E., Baek D., Berndt A., Ryu J. E. Simulation and validation of three dimension functionally graded materials by material jetting, Additive Manufacturing, vol.22, 2018, pp.351-359. [28] Vu I. Q., Bass L. B., Williams C. B., Dillard D. A., Characterizing the effect of print orientation on interface integrity of multimaterial jetting additive manufacturing, Additive Manufacturing, vol. 22, 2018, pp. 447-461.

[29] Shakerin S., Hadadzadeh A., Amirkhiz B. S., Shamsdini S., Li J., Mohammadi M., Additive manufacturing of maraging steelH13 bimetals using laser powder bed fusion technique, Additive Manufacturing, vol. 29, 2019, 100797, in Press.

[30] Boes J., Rottger A., Becker L., Theisen W., Processing of gas-nitrided AISI 316L steel powder by laser powder bed fusionMicrostructure and properties, Additive Manufacturing, vol. 30, 2019, 100836, in press

[31] Chiu Y., Liao Y., Laser path planning of burn-out rule for LOM process, Rapid Prototyping Journal, Vol.9, 2003, pp.201-211

[32]Janaki R.G., Yang Y., Stucker B., Effect of process parameters on bond formation during ultrasonic consolidation of aluminum alloy 3003, Journal of Manufacturing Systems, vol. 25, iss. 3., 2006, pp. 221-238.

[33] Liao Y., Li H., Chiu Y., Study of laminated object 
manufacturing with separately applied heating and pressing, International Journal of Advanced Manufacturing Technology, vol. 27(7-8), 2006, pp.703-707.

[34] Ram G. J., Robinson C., Yang Y., Stucker B., Use of ultrasonic consolidation for fabrication of multi-material structures, Rapid Prototyping Journal, vol. 13(4), 2007, pp. 226-35. [35] Park J., Tari M. J., Hahn H. T., Characterization of the laminated object manufacturing (LOM) process. Rapid Prototyping Journal, vol. 6(1), 2000, pp. 36-50.

[36] Wimpenny D.I., Bryden B., Pashby I.R., Rapid laminated tooling, Journal of Material Processing and Technology, 2003; 138(1):214-8.

[37] Mueller B., Kochan D., Laminated object manufacturing for rapid tooling and patternmaking in foundry industry. Computers in Industry, vol. 39, iss. 1, 1999, pp. 47-53.

[38] Walczyk D. F., Yoo S., Design and fabrication of a laminated thermoforming tool with enhanced features. Journal of Manufacturing Processes vol 11, iss. 1, 2009, pp. 8-18.

[39] Yoon S., Na S., Rapid laminated tooling by a brazing and soldering process, Journal of Manufacturing Processes, vol. 5, iss. 2, 2003, pp. 118-26.

[40] Liao Y., Chiu Y., Adaptive crosshatch approach for the laminated object manufacturing (LOM) process, International Journal of Production Research, vol. 39, iss. 15, 2001, pp. 3479-90. [41] Keshavarzan M., Kadkhodaei M., Badrossamay M., Ravari M. R. K., Investigation on the failure mechanism of triply periodic minimal surface cellular structures fabricated by Vat photopolymerization Additive Manufacturing under compressive loadings, Mechanics of Materials, vol. 140, 2020, 103150, in press. [42] Diptanshu, Miao G., Ma C., Vat photopolymerization 3D printing of ceramics: Effects of fine powder, Manufacturing Letters vol. 21, 2019, pp. 20-23.

[43] Mahamood R.M., Akinlabi E.T., Laser Additive Manufacturing, In Advanced Manufacturing using Laser Material Processing, IGI Global, E.T. Akinlabi, M.R. Mahamood, S.A. Akinlabi (Eds), 2016, pp. 1-23.

[44] Allevia G., Cibeca M., Fioretti R., Marsili R., Montanini R., Rossi G., Qualification of additively manufactured aerospace brackets: A comparison between thermoelastic stress analysis and theoretical results, Measurement, vol. 126, 2018, pp. 252-258

[45]Zanini F., Sbettega E., Carmignato S., X-ray computed tomography for metal additive manufacturing: challenges and solutions for accuracy enhancement, Procedia CIRP 75, 2018, pp. 114-118.

[46] Gao W., Zhanga Y., Ramanujana D., Ramania K., Chenc Y., Williams C. B., Wange C. C. L., Shin Y. C., Zhanga S., Zavattieri P. D., The status, challenges, and future of additive manufacturing in engineering., Computer-Aided Design, vol. 69, 2015, pp. 65-89.

[47] Yadollahi A., Shamsaei N., Additive manufacturing of fatigue resistant materials: Challenges and opportunities, International Journal of Fatigue, vol. 98, 2017, pp. 14-31

[48] Stavropoulos P., Foteinopoulos P., Papacharalampopoulos A., Bikas H., Addressing the challenges for the industrial application of additive manufacturing: Towards a hybrid solution, International Journal of Lightweight Materials and Manufacture, vol. 1, iss. 3, 2018, pp. 157-168.

[49] Ford S., Despeisse M., Additive manufacturing and sustainability: an exploratory study of the advantages and challenges, Journal of Cleaner Production, vol. 137, 2016, pp. 1573-1587

[50] Krujatza F, Lode A., Seidel J., Bley T., Gelinsky M., Steingroewera J. Additive Biotech-Chances, challenges, and recent applications of additive manufacturing technologies in biotechnology, New Biotechnology, vol. 39, 2017, pp. 222-231.

[51] Obielodan J., Stucker B., Characterization of LENSfabricated Ti6Al4V and Ti6Al4V/TiC dual-material transition joints, International Journal of Advanced Manufacturing Technology, vol. 66(9-12), 2013, pp. 2053-2061.

[52] Popoola A. P. I., Ochonogor O. F., Abdulwahab M. Corrosion and Hardness Characteristics of Laser Surface Modified Ti6Al4V/Zr+TiC and Ti6Al4V/Ti+TiC Composites, International Journal of Electrochemical Science, 8, 2013, 2449 - 2458.

[53] Wang F., Mei J., Jiang H., Wu X., Laser fabrication of
Ti6Al4V/TiC composites using simultaneous powder and wire feed, Materials Science and Engineering: A, 2007, pp. 461-466.

[54] Ochonogor O.F., Meacock C., Abdulwahab M., Pityana S.,

Popoola A. P. I., Effects of Ti and TiC ceramic powder on laser cladded Ti-6Al-4V in situ intermetallic composite, Applied Surface Science, vol. 263, 2012, pp. 591-596.

[55] Wang F., Mei J., Wu X., Compositionally graded Ti6Al4V + TiC made by direct laser fabrication using powder and wire, Materials and Design, vol. 28, 2007, pp. 2040-2046.

[56]Zhang Y., Wei Z., Shi L., Xi M. Characterization of laser powder deposited Ti-TiC composites and functional gradient materials. Journal of Materials Processing Technology, vol. 206, 2008, pp. 438-444.

[57] Thivillon L., Bertrand P. H., Laget B., Smurov I., Potential of direct metal deposition technology for manufacturing thick functionally graded coatings and parts for reactors components, Journal of Nuclear Materials, vol. 385(2), 2009, pp. 236-241.

[58]Liu W., DuPont J. N., Fabrication of functionally graded TiC/Ti composite by laser engineered net shaping, Scripta Materialia, vol. 48(9), 2003, pp. 1337-1342.

[59] Shah K., Laser Direct Metal Deposition of Dissimilar and Functionally graded alloys, $\mathrm{PhD}$ Thesis, The University of Manchester, 2011

[60]Lin X., Yue T.M., Yang H.O., Huang W.D., Laser rapid forming of SS316L/Rene88DT graded material, Materials Science and Engineering: A, vol. 391(1-2), 2005, pp. 325-336.

[61] Qin L. Y., Yang G., Wang W., Tong M. Wang X. L. Application of Laser Metal Deposition for Fabrication of Titanium Matrix Wear-Resistant Coating and its Wearing Performance, Applied Mechanics and Materials, vol. 44-47, 2010, pp. 316-320.

[62] Schwendner K.I., Banerjee R., Collins P. C., Brice C.A., Fraser H.L. Direct laser deposition of alloys from elemental powder blends, Scripta Materialia, vol.45(10), 2001, pp.1123-1129. [63] Javaid M., Haleem A., Current status and challenges of Additive manufacturing in orthopaedics: An overview, Journal of Clinical Orthopaedics and Trauma, vol. 10(2), 2019, pp. 380-386

[64] Araya-Calvoa M., López-Gómez I., Chamberlain-Simon N., León-Salazar J. L., Guillén-Girón T., Corrales-Cordero J. S., Sánchez-Brenes O., Evaluation of compressive and flexural properties of continuous fiber fabrication additive manufacturing technology, Additive Manufacturing, vol. 22, 2018, pp. 157-164

[65] Reddy K. V. P., Mirzana I. M., Reddy A. K., Application of Additive Manufacturing technology to an Aerospace component for better trade-off's, Materials Today: Proceedings 5, 2018, pp. 38953902.

[66] Yoo J., Cima M., Khanuja S., Sachs E., Structural ceramic components by $3 D$ printing. In: Solid freeform fabrication symposium, DTIC Document, 1993, pp. 40-50.

[67] Kumar S., Development of functionally graded materials by ultrasonic consolidation, CIRP Journal of Manufacturing Science and Technology, vol. 3(1), 2010, pp. 85-7.

[68]Mahamood R. M., Akinlabi E. T., Achieving Mass Customization through Additive manufacturing, Advances in Ergonomics of Manufacturing: Managing the Enterprise of the Future, C. Schlick and S. Trzcieliński (eds.) Springer International Publishing Switzerland, 2016, pp. 385-390.

[69]Mahamood R. M., Akinlabi E. T., Scanning Speed and Powder Flow Rate on properties Influence on the Properties of LMD Titanium-alloy, International Journal of Mechanical Engineering and Technology, vol. 91(5-8), 2017, pp. 2419-2426, published by Springer.

[70] Akinlabi E. T., Mahamood R. M., Akinlabi S. A., Advanced Manufacturing Techniques Using Laser Material Processing, Hershey, PA: IGI Global, 2016.

[71] Adeyemi A. A., Akinlabi E. T., Mahamood R. M., Microstructural evolution of laser metal deposited 17-4 PH SStungsten composite with varying volume percent tungsten, The Annals of "Dunarea de Jos" University of Galati, Fascicle XII: Welding Equipment and Technology, vol. 29, 2018, pp. 41-46.

[72] Adeyemi A. A., Akinlabi E. T., Mahamood R. M., Influence of Laser Power on the Microhardness and Wear Resistance Properties of Laser Metal Deposited 17-4 Ph Stainless Steel, The Annals of "Dunarea de Jos" University of Galati, Fascicle XII: Welding Equipment and Technology, vol. 29, 2018, pp. 57-63. 